\title{
Decreased Cell Adhesion Promotes Angiogenesis in a Pyk2- dependent Manner
}

\author{
Colette J. Shen ${ }^{1}$, Srivatsan Raghavan ${ }^{1,2}$, Zhe Xu ${ }^{1}$, Jan D. Baranski ${ }^{1}$, Xiang Yu ${ }^{1}$, Michele A. \\ Wozniak $^{1}$, Jordan S. Miller ${ }^{1}$, Mudit Gupta ${ }^{1}$, Leonard Buckbinder ${ }^{3}$, and Christopher S. \\ Chen $^{1,{ }^{*}}$ \\ ${ }^{1}$ Department of Bioengineering, University of Pennsylvania, Philadelphia, PA 19104 \\ ${ }^{2}$ Department of Biomedical Engineering, Johns Hopkins University School of Medicine, Baltimore, \\ MD 21205 \\ ${ }^{3}$ Pfizer Inc., CVMED Exploratory Biology, Groton, CT
}

\begin{abstract}
Angiogenesis is regulated by both soluble growth factors and cellular interactions with the extracellular matrix (ECM). While cell adhesion via integrins has been shown to be required for angiogenesis, the effects of quantitative changes in cell adhesion and spreading against the ECM remain less clear. Here, we show that angiogenic sprouting in natural and engineered threedimensional matrices exhibited a biphasic response, with peak sprouting when adhesion to the matrix was limited to intermediate levels. Examining changes in global gene expression to determine a genetic basis for this response, we demonstrate a vascular endothelial growth factor (VEGF)-induced upregulation of genes associated with vascular invasion and remodeling when cell adhesion was limited, whereas cells on highly adhesive surfaces upregulated genes associated with proliferation. To explore a mechanistic basis for this effect, we turned to focal adhesion kinase (FAK), a central player in adhesion signaling previously implicated in angiogenesis, and its homologue, proline-rich tyrosine kinase 2 (Pyk2). While FAK signaling had some impact, our results suggested that Pyk2 can regulate both gene expression and endothelial sprouting through its enhanced activation by VEGF in limited adhesion contexts. We also demonstrate decreased sprouting of tissue explants from Pyk2-null mice as compared to wild type mice as further confirmation of the role of Pyk2 in angiogenic sprouting. These results suggest a surprising finding that limited cell adhesion can enhance endothelial responsiveness to VEGF and demonstrate a novel role for Pyk2 in the adhesive regulation of angiogenesis.
\end{abstract}

\section{Keywords}

Angiogenesis; cell adhesion; gene expression; Pyk2; VEGF

(C) 2011 Elsevier Inc. All rights reserved.

*Correspondence to Christopher S. Chen, M.D., Ph.D., Department of Bioengineering, University of Pennsylvania, 510 Skirkanich Hall, 210 South 33rd Street, Philadelphia, PA 19104, chrischen@ seas.upenn.edu, Tel: 215-746-1754, Fax: 215-746-1752.

Publisher's Disclaimer: This is a PDF file of an unedited manuscript that has been accepted for publication. As a service to our customers we are providing this early version of the manuscript. The manuscript will undergo copyediting, typesetting, and review of the resulting proof before it is published in its final citable form. Please note that during the production process errors may be discovered which could affect the content, and all legal disclaimers that apply to the journal pertain. 


\section{Introduction}

Angiogenesis, or the formation of new capillary blood vessels during tissue vascularization, involves a coordinated cascade of numerous cellular processes, including the activation of quiescent endothelium leading to degradation of the basement membrane and interstitial matrix, initiation of sprouting from existing vessels via cell proliferation and migration, and coordinated assembly of cells into branching tubules that carry blood [1]. It is therefore not surprising that angiogenesis depends on a complex interplay between soluble growth factors and cellular adhesive interactions with the extracellular matrix (ECM).

While a number of growth factors that promote angiogenesis have been identified, the vascular endothelial growth factor (VEGF) family is perhaps best described due to its roles in stimulating growth, migration, and differentiation of endothelial cells into capillary tubes during both developmental and pathological angiogenesis [2-6]. In contrast to the detailed understanding of the contribution of such growth factors to angiogenesis, much less is known about how cell adhesion to the ECM, and its many complex facets, contributes to the regulation of angiogenesis. Several elegant studies using knockouts or blocking antibodies have demonstrated that integrin-mediated adhesion is an absolute requirement for angiogenesis [7-11]. However, it has also been suggested that more subtle changes in the degree of cell-matrix adhesive interactions can regulate endothelial cell behavior. Early work using purified ECM proteins adsorbed onto substrates demonstrated a profound effect of ECM coating density on endothelial cell function. While saturating concentrations of fibronectin supported maximal endothelial cell proliferation [12], cells cultured on the lowest concentrations that still supported cell attachment rapidly underwent apoptosis even in the presence of saturating concentrations of growth factors [13, 14]. Interestingly, at intermediate concentrations of fibronectin, endothelial cells neither grew nor died but assembled into tube-like structures [13]. Because changes in ECM density impact not only integrin signaling but also the degree of physical cell spreading and flattening against the substrate, it is now thought that both contribute to these effects. Indeed, using micropatterned islands coated with saturating levels of fibronectin to prescribe the area of cell spreading, it has previously been demonstrated that progressively restricting cell spreading (from a 'spread' to 'unspread' to 'round' shape) transitioned endothelial cells from proliferative to tubulogenic to apoptotic responses, recapitulating the observations made by coating substrates with different densities of ECM [15-18].

Here, we examined how changes in cell-ECM adhesion regulate VEGF-induced angiogenic sprouting and used gene expression profiling to further describe these effects. We observed enhanced sprouting and expression of genes associated with an invasive angiogenic phenotype at intermediate levels of adhesion and demonstrate that proline-rich tyrosine kinase 2 (Pyk2, also known as RAFTK, CAK- $\beta$, or CADTK), a FAK family non-receptor tyrosine kinase, is involved in regulating these endothelial functions through its enhanced activation by VEGF in limited adhesion conditions.

\section{Materials and Methods}

Cell culture

Human umbilical vein endothelial cells (HUVECs, provided by Guillermo García-Cardeña, Harvard University) were cultured in Medium 199 (Lonza) containing 20\% fetal bovine serum (FBS, Gibco), 100 units $/ \mathrm{ml}$ penicillin, $100 \mu \mathrm{g} / \mathrm{ml}$ streptomycin, $50 \mu \mathrm{g} / \mathrm{ml}$ ECGS (Biomedical Technologies Inc.), and $100 \mu \mathrm{g} / \mathrm{ml}$ heparin (Sigma) up to passage 7 on gelatincoated culture surfaces. Starvation medium consisted of Medium 199 with 5\% FBS, 100 units $/ \mathrm{ml}$ penicillin, and $100 \mu \mathrm{g} / \mathrm{ml}$ streptomycin. Human adult dermal microvascular endothelial cells (HMVECs, Lonza) were cultured in EGM-2MV medium containing 5\% 
FBS (Lonza). Starvation medium consisted of EGM-2MV containing 0.5\% FBS. Human recombinant VEGF (R\&D Systems) was used at $25 \mathrm{ng} / \mathrm{ml}$ unless noted otherwise.

\section{Reagents}

Adenoviruses harboring GFP, FRNK, and wild-type FAK were generated as described previously [19], with wild-type FAK adenovirus used at a MOI of 3 and FRNK adenovirus used at a MOI of 10. Adenoviruses for expression of $\beta$-galactosidase (control) and Pyk2 shRNA, as well as wild-type Pyk2, were provided by Pfizer. Cells were infected with wildtype Pyk2 and Pyk2 shRNA adenoviruses at a MOI of 200. The FAK inhibitor PF-573228 (Tocris Bioscience) and the Pyk2 inhibitor PF-4594755 (gift, Pfizer) were used at $500 \mathrm{nM}$ unless noted otherwise.

\section{Sprouting assays}

Aortic ring sprouting from chick embryonic aortas into fibrin and PEGDAAm (poly(ethylene glycol) diacrylamide) gels was carried out using a modification of a protocol described previously [20]. Aortic arches were isolated from 12-day-old white Leghorn chick embryos (Charles River SPAFAS, Preston, CT), dissected into $1 \mathrm{~mm}$-long segments, and embedded into fibrin gels (human fibrinogen and thrombin from Sigma) of defined density or PEGDAAm gels of varying RGD density (described below). Gels were maintained in EGM-2 medium (Lonza) and imaged 48 hours later on an inverted microscope (Nikon Eclipse TE200) with SPOT RT3 camera (Diagnostic Instruments, Inc.). Sprout lengths were quantified using Image J software (National Institutes of Health). For high-magnification imaging of endothelial cells in the sprouts, aortic rings were incubated with $20 \mu \mathrm{g} / \mathrm{ml}$ rhodamine-labeled lectin (Lens culinaris agglutinin; Vector Laboratories) for 30 minutes in EBM-2 prior to embedding. After 48 hours in culture, samples were fixed in $4 \%$ paraformaldehyde, labeled with Hoechst 33342, and imaged using a Zeiss LSM 710 laser scanning confocal microscope with a $40 \mathrm{X}$ objective.

\section{Synthesis and characterization of poly(ethylene glycol) diacrylamide (PEGDAAm) gels}

Degradable PEGDAAm gels of varying RGDS adhesive ligand density used for aortic ring sprouting assays were synthesized, characterized, and polymerized as described previously [21], with the exception that PEGDAAm instead of PEGDA (poly(ethylene glycol) diacrylate) gels were used. $3 \%$ w/w PEGDAAm gels incorporating highly degradable MMPsensitive peptide sequences were used for all experiments, with varying amounts of adhesive RGDS ligand supplemented by non-adhesive RGES ligand covalently immobilized such that total ligand density was held constant between all conditions. To obtain the shear modulus of PEG gels, gel samples were polymerized and covalently linked to glass slides and then swollen in PBS for 36 hours. Measurements were obtained using an AR 2000 oscillating rheometer (TA Instruments) at 10-20\% axial compression, a frequency of $1 \mathrm{~Hz}$, and a strain of $1 \%$.

\section{Generation of Pyk2 knockout mice and mouse aortic ring sprouting assay}

C57BL/6 Pyk2+/- mice were generated according to a method described previously [22] and were a generous gift from Dr. Charles Turner (Indiana University). Heterozygous mice were intercrossed to produce homozygous Pyk2-/- mice. Genotyping was performed using the following primers: Pyk2 wild type forward, 5'-

GGAGGTCTATGAAGGTGTCTACACGAAC-3'; Pyk2 mutant forward, 5'GCCAGCTCATTCCTCCCACTCAT-3'; Pyk2 reverse, 5' CCTGCTGGCAGCCTAACCACAT-3'. 
The mouse aortic ring sprouting assay was carried out following a protocol described previously [20]. Briefly, aortas were harvested from 1 to 2-month-old wild type or Pyk2-/C57BL/6 mice and sectioned into $1 \mathrm{~mm}$-long pieces. Rings were embedded in $2.5 \mathrm{mg} / \mathrm{ml}$ collagen I (rat tail collagen I from BD Biosciences), and samples were exposed to vacuum to remove air bubbles prior to gelation. Samples were maintained in EBM-2 medium (Lonza) with $2.5 \% \mathrm{FBS}, 50 \mathrm{ng} / \mathrm{ml}$ recombinant human VEGF (R\&D Systems), and $50 \mathrm{ng} / \mathrm{ml}$ recombinant murine HGF (R\&D Systems) and imaged 8 days later on an inverted microscope (Nikon Eclipse TE200) with SPOT RT3 camera (Diagnostic Instruments, Inc.).

\section{Generation of micropatterned and fibronectin-coated substrates}

Micropatterned substrates to control cell adhesion were generated as previously described [23]. Briefly, stamps containing arrays of squares were generated by casting poly(dimethylsiloxane) (PDMS; Sylgard 184, Dow Corning) from silicon masters patterned by photolithography. Stamps were immersed for 1 hour in an aqueous solution of $20 \mu \mathrm{g} / \mathrm{ml}$ fibronectin (BD Biosciences), rinsed three times in water, and blown dry with nitrogen. They were then placed in conformal contact against UV ozone-treated PDMS-coated culture surfaces, which were then blocked with 0.2\% Pluronic F127 (BASF) for 1 hour and rinsed with PBS before cell seeding. Substrates with different densities of adsorbed fibronectin were generated by immersing PDMS-coated surfaces in the specified concentration of fibronectin for 1 hour, rinsing two times in water, blocking in $0.2 \%$ Pluronic F127 for 1 hour, and rinsing in PBS before cell seeding.

\section{Microarray analysis}

HUVECs were cultured on micropatterned islands $\left(1764 \mu \mathrm{m}^{2}\right)$ of fibronectin or allowed to spread fully for 2 hours and then stimulated with $50 \mathrm{ng} / \mathrm{ml}$ VEGF or no growth factor for 18 hours in starvation medium. Sample RNA from each of 3 replicates was isolated using the Qiagen RNeasy Mini Kit and prepared for hybridization to microarrays as described in the Affymetrix GeneChip Expression Analysis Technical Manual. Briefly, $2 \mu \mathrm{g}$ of total RNA was converted to first-strand cDNA using Superscript II reverse transcriptase primed by a poly(T) oligomer that incorporated the T7 promoter. Second-strand cDNA synthesis was followed by in vitro transcription for linear amplification of each transcript and incorporation of biotinylated CTP and UTP. The cRNA products were fragmented to 200 nucleotides or less, heated at $99^{\circ} \mathrm{C}$ for 5 minutes and hybridized for 16 hours at $45^{\circ} \mathrm{C}$ to Affymetrix Human Genome U133 Plus 2.0 GeneChip expression microarrays. The microarrays were then washed at low (6X SSPE) and high (100 mM MES, $0.1 \mathrm{M} \mathrm{NaCl}$ ) stringency and stained with streptavidin-phycoerythrin. Fluorescence was amplified by adding biotinylated anti-streptavidin and an additional aliquot of streptavidin-phycoerythrin stain. A confocal scanner was used to collect fluorescence signal at $3 \mu \mathrm{m}$ resolution after excitation at $570 \mathrm{~nm}$. The average signal from two sequential scans was calculated for each microarray feature. GCRMA-normalized expression data from each microarray were deposited in NCBI's Gene Expression Omnibus and are accessible through GEO Series accession number GSE19098 at the following link:

http://www.ncbi.nlm.nih.gov/geo/query/acc.cgi?acc=GSE19098. All data are MIAME compliant.

\section{Real-time gene expression analysis}

Sample RNA was isolated using the Qiagen RNeasy Micro Kit, then quantified using a UV spectrophotometer (Becton Dickinson) at $260 \mathrm{~nm}$ and $280 \mathrm{~nm}$. RNA was then reversetranscribed using M-MLV RT (Invitrogen), and the resulting cDNA was amplified using Taqman gene expression assay primers (Applied Biosystems) on an Applied Biosystems 7300 real-time PCR instrument. Gene expression values represent $2^{-\Delta \Delta \mathrm{Ct}}$, normalized to 
GAPDH and the indicated spread or high fibronectin density control condition in all experiments.

\section{Quantification of focal adhesions}

Focal adhesions were quantified as previously described [24]. Briefly, cells were incubated for 1 minute in ice-cold cytoskeleton buffer $\left(50 \mathrm{mM} \mathrm{NaCl}, 150 \mathrm{mM}\right.$ sucrose, $3 \mathrm{mM} \mathrm{MgCl} \mathrm{M}_{2}$, $1 \mu \mathrm{g} / \mathrm{ml}$ aprotinin, $1 \mu \mathrm{g} / \mathrm{ml}$ leupeptin, $1 \mu \mathrm{g} / \mathrm{ml}$ pepstatin, and $2 \mathrm{mM}$ PMSF), followed by 1 minute in cytoskeleton buffer containing $0.5 \%$ Triton X-100. Detergent-extracted cells were fixed in 4\% paraformaldehyde in PBS for 20 minutes, blocked in 33\% goat serum for 1 hour, and incubated with a primary antibody to vinculin (hVin1, Sigma-Aldrich), followed by incubation with Alexa Fluor 594-conjugated secondary antibodies (Invitrogen). Samples were imaged on an inverted microscope (Zeiss Axiovert 200M) with a $63 \times 1.40 \mathrm{NA}$, oil immersion objective and a Zeiss AxioCamHRm camera using Zeiss AxioVision software. Images were filtered and binarized using Matlab, and adhesions over $0.5 \mu \mathrm{m}^{2}$ counted toward the overall focal adhesion number per cell.

\section{Immunoblotting}

Cells were rinsed in PBS and lysed in ice-cold RIPA buffer (1\% Triton X-100, $150 \mathrm{mM}$ sodium chloride, $0.5 \%$ sodium deoxycholate, $0.1 \%$ SDS, $50 \mathrm{mM}$ Tris $\mathrm{pH} 8.0,1 \mathrm{mM}$ sodium orthovanadate, $5 \%(\mathrm{v} / \mathrm{v}) \beta$-mercaptoethanol, and $1 \mu \mathrm{g} / \mathrm{ml}$ each aprotinin, leupeptin, pepstatin, and PMSF). Proteins were separated by SDS-PAGE, transferred to PVDF membranes, and blocked with 5\% BSA or 5\% milk in TBS-T as recommended for each antibody. Blots were probed with antibodies against total FAK (clone 77, BD Biosciences), phosphorylated FAK (Y397, Biosource), FRNK (06-543, Millipore), total Pyk2 (clone 11, BD Biosciences; 06-559, Millipore), phosphorylated Pyk2 (Y402, Biosource), GAPDH (clone 6C5, Ambion), and $\alpha$-tubulin (clone B-5-1-2, Sigma) followed by horse radish peroxidase-conjugated secondary antibodies (Jackson ImmunoResearch) and SuperSignal West Dura chemiluminescent detection (Pierce). Densitometric analysis was performed using a VersaDoc digital imaging system with QuantityOne software (BioRad).

\section{Results}

\section{Decreased adhesive ligand density enhances angiogenic sprouting}

To begin to explore the effects of modulating cell-ECM adhesion on angiogenic sprouting, we adopted a simple but robust classical assay in which explanted embryonic chick aortic arches (E12) are sectioned into rings and embedded into fibrin gels [20]. In this model, endothelial cells within the aortic tissue rapidly invade the surrounding fibrin, in the form of multicellular, tube-like structures. To examine the effect of changing adhesion, we varied the density of fibrin by polymerizing gels with fibrinogen ranging from 5 to $20 \mathrm{mg} / \mathrm{ml}$. We observed significantly enhanced sprouting in low density as compared to high density fibrin gels (Fig. 1A,C), with the average length of sprouts in $5 \mathrm{mg} / \mathrm{ml}$ fibrin gels twice that in 20 $\mathrm{mg} / \mathrm{ml}$ fibrin gels by 48 hours. Interestingly, not just the degree but also the character of sprouting appeared to be modulated by adhesion, with longer, more sparsely arranged sprouts in low density fibrin gels contrasting shorter, more densely packed sprouts in high density fibrin gels. Labeling the samples with an endothelial cell-specific lectin confirmed that the majority of cells within the sprouts were endothelial cells (Fig. 1B).

Varying fibrin density alters the density of crosslinks and the mechanical properties of the gels as well as adhesive ligand density (here, while ligand density is altered 4-fold, mechanical compliance is altered approximately 2.5 -fold [25]). Indeed, others have observed changes in sprouting or vascular assembly with varying densities of fibrin, collagen, and Matrigel and have attributed these effects to differences in matrix stiffness or diffusivity 
[26-29]. To eliminate the potential confounding effects of altered crosslinking, we assessed sprouting in a synthetic hydrogel ECM, poly(ethylene glycol) diacrylamide (PEGDAAm), in which adhesive ligand density can be altered as an independent variable. We varied the density of the adhesive ligand RGDS immobilized within otherwise identical PEGDAAm gels that contained a matrix metalloproteinase-sensitive peptide inserted into the backbone of the matrix, allowing for cell-mediated invasion through the engineered ECM. As it has previously been suggested that incorporation of peptide ligands can affect the mechanical properties of PEG gels [30], the total amount of immobilized ligand was kept constant between conditions through the incorporation of the non-adhesive RGES peptide such that the final adhesive RGDS plus non-adhesive RGES ligand density remained constant. We confirmed that the mechanical properties of the gels did not significantly vary with changes in RGDS density through rheological measurements (Fig. S1). In this setting, we observed a biphasic sprouting response to changes in adhesive ligand density: the complete absence of adhesive ligand (which could not be achieved with fibrin gels) did not permit any sprouting, while sprouting was promoted at an intermediate ligand density of $1 \mu \mathrm{mol} / \mathrm{ml}$ RGDS and again decreased at a higher RGDS density of $10 \mu \mathrm{mol} / \mathrm{ml}$ (Fig. 1D,E). Thus, while the effect of ECM on angiogenesis is likely multifactorial and includes factors such as matrix stiffness and diffusivity, our results demonstrate that adhesive ligand density also plays an important role in regulating angiogenic sprouting and that this effect is biphasic in nature.

\section{Cell adhesion and spreading regulate the expression of genes associated with angiogenesis}

We next examined whether more precise methods to limit the degree of cell adhesion could similarly induce an activated angiogenic phenotype. We utilized two approaches to modulate cell-ECM adhesion: one involves coating cell culture substrates with different densities of fibronectin to control ECM availability [13], and the other involves micropatterning substrates with different sizes of fibronectin-coated islands to control the physical area of cell-ECM contact [15]. Because our sprouting studies revealed increased invasion with decreased adhesive ligand density, we selected adhesive conditions for this study in which adhesion would be either maximal or approximately half of maximal, as measured by quantification of focal adhesions. We cultured human umbilical vein endothelial cells (HUVECs) on micropatterned islands of fibronectin $\left(1764 \mu \mathrm{m}^{2}\right.$, "unspread") or low density $\left(5 \mu \mathrm{g} / \mathrm{ml}\right.$ ) fibronectin (average cell spreading area $1750 \mu \mathrm{m}^{2}$ ), as compared to cells allowed to spread fully on surfaces coated with high density $(20 \mu \mathrm{g} / \mathrm{ml})$ fibronectin (average area $3200 \mu \mathrm{m}^{2}$, "spread"). Staining for focal adhesions verified that both unspread cells and cells cultured on low density fibronectin had significantly fewer adhesions than spread cells (Fig. 2A).

While these well-defined adhesive contexts offer an approach to isolate the specific effects of cell-ECM adhesion, they do not support the complex invasion and sprouting behavior observed in the fibrin gels. As such, to better characterize the phenotype of endothelial cells cultured on these substrates, we examined global gene expression changes by microarray analysis. We compared limited versus high adhesion by culturing HUVECs on micropatterned islands of fibronectin $\left(1764 \mu \mathrm{m}^{2}\right.$, "unspread") to represent intermediate levels of cell spreading or allowed to spread fully (average area $3200 \mu \mathrm{m}^{2}$, "spread") for 2 hours and then stimulated with $50 \mathrm{ng} / \mathrm{ml}$ VEGF or no growth factor for 18 hours in starvation medium. ANOVA analysis indicated that many genes $(1,641$ out of 28,970$)$ changed expression at least 2 -fold in response to changes in spreading alone. In contrast, only a small subset of genes (108) was upregulated at least 2-fold in response to VEGF in highly adherent, well-spread cells, highlighting the dramatic effects of adhesion on global gene expression in endothelial cells. Interestingly, substantially more genes (521) responded 
to VEGF in unspread cells, indirectly hinting at the possibility that the response to VEGF may be enhanced in the context of limited cell adhesion.

Importantly, when focusing only on genes previously associated with angiogenesis (genes associated with Gene Ontology category of angiogenesis, as well as genes previously described to be upregulated in models of angiogenesis [31,32]), a majority were upregulated in unspread cells as compared to spread cells (Fig. 2B). These upregulated genes primarily belonged to functional groupings such as angiogenic growth factor signaling, cell-ECM adhesion and migration, cell-cell adhesion, and matrix invasion. Together, this constellation was representative of an activated angiogenic phenotype. In contrast, genes upregulated in spread cells were primarily associated with proliferation. These results were consistent with previous studies demonstrating a switch between proliferation and tubulogenesis with changes in spreading $[12,13,15]$ and suggested the possibility of genetic markers representing functional differences in endothelial cell behavior.

We confirmed the expression of several genes by quantitative real-time PCR (Fig. 2C), including: Eph receptor A7 (EPHA7), a member of the ephrin tyrosine kinase receptor family that, along with ephrin ligands, mediate cell-cell communication important for vessel sprouting and morphogenesis [33]; stanniocalcin 1 (STC1), a gene involved in endothelial cell migration [34] and highly upregulated in several microarrays of angiogenesis [31, 32]; membrane type 1 MMP (MMP14), a matrix metalloproteinase required for vascular invasion [35, 36]; and cyclin D1 (CCND1), a cyclin required for G1/S progression in the cell cycle known to regulate endothelial cell proliferation [37]. The same results were observed in a second endothelial cell type, human microvascular endothelial cells (HMVECs), as well as in HUVECs cultured on high versus low densities of fibronectin (Fig. S2), demonstrating that limiting cell adhesion through multiple mechanisms, whether via changes in cell spreading or ligand density, induced the expression of genes associated with the invasive processes of angiogenesis. Given the consistency of results between the two different methods to control cell adhesion, we employ both of them in subsequent experiments. Micropatterned islands allow for more precise control of cell spreading and adhesion and were therefore used as our primary manipulation of adhesion. In contrast, altering fibronectin density in a two-dimensional setting represents a closer tie to studies altering adhesive ligand density in three-dimensional gels and were used to confirm key results, as well as in settings where large numbers of cells were required.

\section{FAK is not a major regulator of limited adhesion-induced angiogenic gene expression}

To begin to explore potential signaling pathways responsible for transducing changes in adhesion and spreading into changes in gene expression, we first turned to FAK, which is known to transduce both soluble growth factor and adhesive signals in angiogenesis [38] and is required for embryonic vascular development in vivo [39, 40]. We first confirmed that FAK phosphorylation is promoted by increased cell adhesion and VEGF stimulation (Fig. $3 \mathrm{~A}$ ), consistent with previous reports [19, 38, 41]. To investigate the role of FAK in VEGFinduced gene expression, we expressed wild-type FAK or FRNK, the dominant-negative Cterminal fragment of FAK, in HUVECs using recombinant adenoviruses and confirmed that these treatments increased or decreased FAK signaling, respectively (Fig. 3B). FAK-, FRNK-, and control GFP-expressing cells were cultured in spread or unspread conditions with or without VEGF exposure for 16-18 hours and analyzed for gene expression. FAK manipulation had no significant effect on the expression of CCND1. Interestingly, the only statistically significant change was rescue of VEGF-induced STC1 expression in FRNKexpressing spread cells to levels greater than in control unspread cells (Fig. 3C), though EPHA7 appeared to trend upwards with FRNK expression. Overexpression of FAK, which leads to increased FAK activity (opposite to the effect of FRNK), surprisingly had no significant effect though also led to an upward trend in STC1 and EPHA7 expression. These 
data suggested that FAK may have at best some minor role in the observed angiogenic gene expression response to limited adhesion.

\section{Pyk2 regulates the expression of genes associated with angiogenesis}

While endothelial cell-specific knockout of FAK has been shown to be embryonic lethal $[39,40]$, inducible knockout of FAK in adult endothelial cells does not affect angiogenesis due to a compensatory upregulation of its structurally related homologue, Pyk2 [42]. Pyk2 is activated by a number of extracellular signals, including growth factors and ECM adhesion $[43,44]$. However, unlike FAK, which is ubiquitously expressed, Pyk2 is restricted to primarily hematopoietic and neuronal tissues, with upregulation in a broader group of tissues only later in development $[45,46]$, and thus its role in angiogenesis has not been fully characterized. In addition to its compensatory role for FAK in adult angiogenesis, Pyk2 has been shown to be involved in endothelial cell spreading and migration [41], VE-cadherinmediated cell-cell adhesion [47], and neovessel formation [48, 49]. However, the effect of different adhesive contexts on its role in angiogenesis has not been explored.

We first investigated whether changes in adhesion regulate Pyk2 phosphorylation in endothelial cells by measuring Pyk2 phosphorylation in response to VEGF in HUVECs cultured on high and low densities of fibronectin. We observed a two-fold increase in phosphorylation in cells cultured on low density versus high density fibronectin (Fig. 4A), suggesting that reduced adhesion enhances Pyk2 activation by VEGF, in contrast to FAK (Fig. 3A). To investigate the role of Pyk2 in regulating angiogenic gene expression in different adhesive contexts, we first knocked down expression of Pyk 2 using a targeted shRNA (Fig. 4B) and cultured Pyk2 and control ( $\beta$-gal) shRNA-expressing HUVECs in spread or unspread conditions with or without VEGF exposure for 16-18 hours. Pyk2 knockdown led to a significant decrease in the expression of EPHA7 and STC1 in unspread cells exposed to VEGF, to levels similar to wild type spread cells stimulated with VEGF (Fig. 4D). While these data suggest that Pyk2 is necessary for VEGF-induced gene expression in limited adhesive contexts, it is not clear whether Pyk2 signaling is sufficient for controlling angiogenic gene expression. To address this possibility, we overexpressed wild-type Pyk2 (Fig. 4C) and placed cells in high versus low adhesive contexts, with and without VEGF stimulation. Although Pyk2 alone could not initiate angiogenic gene expression, it rescued EPHA7 and STC1 expression in fully spread cells in response to VEGF (Fig. 4E), indicating Pyk2 was necessary and sufficient for transducing the low adhesive context that supports VEGF responsiveness. We noted a slight decrease in FAK phosphorylation with overexpression of wild-type Pyk2, which has been previously reported [50]. However, because we did not observe a major effect from the direct manipulation of FAK, this compensatory change in FAK following Pyk2 manipulation is not likely a central mechanism for the effects of Pyk2 signaling. Interestingly, CCND1 expression was not affected by Pyk 2 manipulation, suggesting that only genes normally upregulated by decreased adhesion and associated with an activated endothelial phenotype-and not those associated with proliferation-are regulated by Pyk2.

\section{Pyk2 regulates angiogenic sprouting}

Our studies uncovered a role for Pyk2 in regulating the expression of several genes involved in angiogenesis. However, it remained unclear whether these effects on gene expression would ultimately impact the physical process of angiogenic sprouting observed earlier. As such, we examined the effects of Pyk2 and FAK manipulation on sprouting in the chick aortic ring model in fibrin gels. We were unable to use our mutant constructs or siRNA methods with the chick aortic rings, so we inhibited Pyk2 with the pharmacological inhibitor PF-4594755 ("PF755" [50]) and FAK with the pharmacological inhibitor PF-573228 ("PF228" [51]), choosing concentrations based on maximal inhibition of the target kinase 
and minimal inhibition of the other (Fig. S3). Pyk2 inhibition with PF755 significantly reduced sprouting in both low and high density fibrin gels. FAK inhibition with PF228 also inhibited sprouting in low density gels, resulting in a synergistic reduction of sprouting with the two inhibitors together (Fig. 5A,B). These results confirm a role for Pyk2, and to a lesser extent FAK, in regulating adhesion-dependent angiogenic sprouting.

While pharmacological manipulation uncovered a role for Pyk2 in regulating sprouting angiogenesis, we wanted to confirm this finding using a more specific manipulation of Pyk2. To this end, we measured sprouting from aortic rings isolated from Pyk2 knockout versus wild type mice. The percent of aortic rings sprouting was significantly decreased in rings isolated from Pyk2 knockout mice (55\%) as compared to wild type mice (89\%) (Fig. 5C,D), confirming an important role for Pyk2 in regulating angiogenic sprouting in an ex vivo setting.

\section{Discussion}

\section{The role of multiple adhesive states in angiogenesis}

Previous studies have demonstrated enhanced endothelial cell proliferation with increased cell spreading and ECM density $[12,15]$, and inhibition of either endothelial proliferation or cell-ECM adhesion are proven mainstay strategies for developing anti-angiogenic therapies $[8,52]$. As a result, it has largely been assumed that angiogenesis would be optimal in highly adhesive contexts. It was therefore unexpected that we initially observed a role for limited adhesion in promoting capillary sprouting. Previous reports had described increased tubulogenesis with limited cell adhesion and spreading in vitro in assays reminiscent of vasculogenesis $[13,18]$, but the relevance of these findings to angiogenesis had remained unclear. Interestingly, here we revealed that limited adhesion drives sprouting in part by stimulating an activated endothelial phenotype associated with vascular invasion and remodeling, which can now be characterized by a specific gene expression profile. It has recently been shown that increasing matrix compliance, which in other studies is thought to suppress integrin activation [53], appears to enhance VEGF responsiveness of endothelial cells and angiogenesis in vivo [27]. Another recent study has also reported that low concentrations of integrin antagonists, under development as anti-angiogenic cancer therapeutics, actually promote angiogenesis [54]. Our studies here point to one mechanism by which both the matrix compliance and integrin antagonist effects could be explained.

In our studies, we observed a biphasic angiogenic response to changes in adhesive ligand density, supportive of studies showing an analogous effect in response to matrix compliance and integrin antagonists $[27,54]$. While cells cannot adhere to and invade a scaffold that completely lacks adhesive ligand, there appears to be an intermediate level of adhesion at which angiogenic sprouting is optimal. In this study we did not identify a precise ligand density at which sprouting would be maximal in our system, as this would likely only be specific for the exact synthetic scaffold formulation used in our study. However, more detailed quantitative studies of ligand density effects on angiogenesis - in relation to other material properties including matrix stiffness, diffusivity, and degradability — would be warranted in future investigations.

The fact that differences in the degree of cell-ECM adhesion could promote distinct (proliferative versus invasive) endothelial cell behaviors important for angiogenesis may have implications in numerous settings. Because angiogenesis is a complex, multi-step process, it is possible that these different cellular behaviors are stimulated in different stages of angiogenesis: enhanced MMP production and ECM degradation at the sprouting tips [55] could limit adhesion and thereby promote migration and cellular invasion, and increased ECM deposition along the stalks could be responsible for the observed proliferation in these 
regions [56]. Notably, our microarray analysis identified upregulation of genes associated with tip cells-VEGFR-2/KDR, PDGF-B, and MT1-MMP/MMP14 [55, 56]—in cells with limited adhesion exposed to VEGF, suggesting that adhesive gradients may indeed play an important role in dictating the diverse cell behaviors that are coordinated along angiogenic sprouts. Extending these implications to the pathologic settings of matrix-dense tumors and fibrotic tissue, it is possible that the altered degree of adhesive interactions may contribute to the abnormal angiogenesis in these settings as much as excessive soluble growth factor stimulation, which is widely cited as a key promoter of pathological angiogenesis $[6,57]$.

\section{The roles of Pyk2 versus FAK in angiogenesis}

Previous studies have suggested that FAK and Pyk2 have overlapping and redundant functions in regulating angiogenesis. While the endothelial-specific FAK knockout is embryonic lethal $[39,40]$, conditional knockout in adults results in no abnormal phenotype due to a compensatory mechanism in which Pyk2 upregulation rescues angiogenesis [42]. Interestingly, while Pyk2-null mice have no overt developmental vascular defects, hindlimb reperfusion after ischemia is impaired, and Pyk2-null endothelial cell migration and tubulogenesis are defective [48]. Our own results demonstrate impaired angiogenic sprouting from aortic rings isolated from adult Pyk2-knockout mice. The importance of Pyk2 only in adult angiogenesis could be explained by its lack of expression in embryonic endothelium [45], whereas FAK is always expressed.

Our results indicate FAK and Pyk2 may be responsible for different aspects of angiogenesis depending on the adhesive context. We show that Pyk2 phosphorylation is upregulated with decreased adhesion and that it is responsible for promoting angiogenic gene expression and sprouting in limited adhesive contexts. In contrast, FAK phosphorylation is increased with greater cell adhesion and spreading $[19,58]$, has little effect on modulating the expression of angiogenic genes associated with endothelial invasion and migration, but appears to be important for regulating endothelial cell proliferation [19, 59]. Thus, FAK and Pyk2 may be responsible for differences in the regulation and character of angiogenesis in developmental versus adult settings as well as in high versus low density matrices. This balance between the two homologues may even explain observed differences in endothelial cell behaviors within a single angiogenic sprout as a result of local gradients in the adhesive cues present, in which cells in the stalk are surrounded by a more developed ECM and proliferate while cells at the tip are degrading ECM and taking on a more invasive phenotype.

Although FAK and Pyk2 are homologues with some structural and sequence similarity, they have distinct characteristics that could explain their individual functions in the context of angiogenesis. The increase in Pyk2 phosphorylation with decreased adhesion could potentially result from a direct competition with binding partners of FAK. Adhesion is thought to increase FAK signaling in part by co-localizing FAK signaling partners to assembling focal adhesions [60]. Pyk2, with its more cytoplasmic distribution as compared to FAK [44], may therefore better access upstream and downstream signaling partners when they are not sequestered into focal adhesions. Its increased phosphorylation with limited adhesion only in the presence of VEGF could reflect a requirement for both VEGF stimulation and adhesion-regulated interactions with binding partners for maximal activation, or perhaps that interaction with binding partners occurs only upon VEGF stimulation. Other possible mechanisms, such as the activation of a phosphatase limiting Pyk2 activity in highly adhesive cells, could also be explored.

It will ultimately be important to determine how Pyk2 signals downstream to promote expression of invasive angiogenic genes. It has been shown that STC1 expression in endothelial cells requires MAPK and PKC signaling [61], and it is known that Pyk2 signals downstream to both pathways [62]. Possible transcriptional regulators of angiogenic gene 
expression include JAK/STAT5A, shown to be activated in endothelial cells by integrinmediated cell adhesion [63] and VEGF [64], as well as HOXA13, known to regulate EPHA7 expression [65]. Whether a central mechanism or multiple parallel signaling pathways and transcriptional regulators are responsible for the regulation of angiogenic genes by limited adhesion remains to be determined.

\section{Conclusions}

Here, we report a role for limited endothelial adhesion in promoting an invasive angiogenic gene expression profile and capillary sprouting, and demonstrate that Pyk2 plays a critical role in mediating these effects. These findings further suggest the existence of a balance between invasive and proliferative phenotypes regulated by cell adhesion, which is potentially mediated by a balance between Pyk2 and FAK signaling. Thus, while it has previously been shown that integrins and integrin-mediated adhesion are required for angiogenesis, the data presented here suggest a substantially more subtle interplay between changes in the degree of adhesion and endothelial cell phenotypes, which likely contributes to the complex staging of multiple behaviors necessary to generate new capillary beds.

\section{Supplementary Material}

Refer to Web version on PubMed Central for supplementary material.

\section{Acknowledgments}

The authors are grateful to Charles Turner (Indiana University) for providing C57BL/6 Pyk2 heterozygous mice, the Penn Microarray Facility for microarray analysis and Guillermo García-Cardeña for providing HUVECs. We thank W. Legant, R. Desai, J. Leight, and J. Eyckmans for helpful discussions and careful reading of the manuscript.

\section{References}

1. Adams RH, Alitalo K. Molecular regulation of angiogenesis and lymphangiogenesis. Nat Rev Mol Cell Biol. 2007; 8:464-478. [PubMed: 17522591]

2. Ferrara N, Gerber HP, LeCouter J. The biology of VEGF and its receptors. Nat Med. 2003; 9:669676. [PubMed: 12778165]

3. Carmeliet P, Ferreira V, Breier G, Pollefeyt S, Kieckens L, Gertsenstein M, Fahrig M, Vandenhoeck A, Harpal K, Eberhardt C, Declercq C, Pawling J, Moons L, Collen D, Risau W, Nagy A. Abnormal blood vessel development and lethality in embryos lacking a single VEGF allele. Nature. 1996; 380:435-439. [PubMed: 8602241]

4. Ferrara N, Carver-Moore K, Chen H, Dowd M, Lu L, O'Shea KS, Powell- Braxton L, Hillan KJ, Moore MW. Heterozygous embryonic lethality induced by targeted inactivation of the VEGF gene. Nature. 1996; 380:439-442. [PubMed: 8602242]

5. Miquerol L, Langille BL, Nagy A. Embryonic development is disrupted by modest increases in vascular endothelial growth factor gene expression. Development. 2000; 127:3941-3946. [PubMed: 10952892]

6. Ozawa CR, Banfi A, Glazer NL, Thurston G, Springer ML, Kraft PE, McDonald DM, Blau HM. Microenvironmental VEGF concentration, not total dose, determines a threshold between normal and aberrant angiogenesis. J Clin Invest. 2004; 113:516-527. [PubMed: 14966561]

7. Friedlander M, Brooks PC, Shaffer RW, Kincaid CM, Varner JA, Cheresh DA. Definition of two angiogenic pathways by distinct alpha v integrins. Science. 1995; 270:1500-1502. [PubMed: 7491498]

8. Avraamides CJ, Garmy-Susini B, Varner JA. Integrins in angiogenesis and lymphangiogenesis. Nat Rev Cancer. 2008; 8:604-617. [PubMed: 18497750] 
9. Kim S, Bell K, Mousa SA, Varner JA. Regulation of angiogenesis in vivo by ligation of integrin alpha5beta1 with the central cell-binding domain of fibronectin. Am J Pathol. 2000; 156:13451362. [PubMed: 10751360]

10. Tanjore H, Zeisberg EM, Gerami-Naini B, Kalluri R. Beta1 integrin expression on endothelial cells is required for angiogenesis but not for vasculogenesis. Dev Dyn. 2008; 237:75-82. [PubMed: 18058911]

11. Yang JT, Rayburn H, Hynes RO. Embryonic mesodermal defects in alpha 5 integrin-deficient mice. Development. 1993; 119:1093-1105. [PubMed: 7508365]

12. Ingber DE. Fibronectin controls capillary endothelial cell growth by modulating cell shape. Proc Natl Acad Sci U S A. 1990; 87:3579-3583. [PubMed: 2333303]

13. Ingber DE, Folkman J. Mechanochemical switching between growth and differentiation during fibroblast growth factor-stimulated angiogenesis in vitro: role of extracellular matrix. J Cell Biol. 1989; 109:317-330. [PubMed: 2473081]

14. Re F, Zanetti A, Sironi M, Polentarutti N, Lanfrancone L, Dejana E, Colotta F. Inhibition of anchorage-dependent cell spreading triggers apoptosis in cultured human endothelial cells. J Cell Biol. 1994; 127:537-546. [PubMed: 7523422]

15. Chen CS, Mrksich M, Huang S, Whitesides GM, Ingber DE. Geometric control of cell life and death. Science. 1997; 276:1425-1428. [PubMed: 9162012]

16. Chen CS, Mrksich M, Huang S, Whitesides GM, Ingber DE. Micropatterned surfaces for control of cell shape, position, and function. Biotechnol Prog. 1998; 14:356-363. [PubMed: 9622515]

17. Huang S, Chen CS, Ingber DE. Control of cyclin D1, p27(Kip1), and cell cycle progression in human capillary endothelial cells by cell shape and cytoskeletal tension. Mol Biol Cell. 1998; 9:3179-3193. [PubMed: 9802905]

18. Dike LE, Chen CS, Mrksich M, Tien J, Whitesides GM, Ingber DE. Geometric control of switching between growth, apoptosis, and differentiation during angiogenesis using micropatterned substrates. In Vitro Cell Dev Biol Anim. 1999; 35:441-448. [PubMed: 10501083]

19. Pirone DM, Liu WF, Ruiz SA, Gao L, Raghavan S, Lemmon CA, Romer LH, Chen CS. An inhibitory role for FAK in regulating proliferation: a link between limited adhesion and RhoAROCK signaling. J Cell Biol. 2006; 174:277-288. [PubMed: 16847103]

20. Aplin AC, Fogel E, Zorzi P, Nicosia RF. The aortic ring model of angiogenesis. Methods Enzymol. 2008; 443:119-136. [PubMed: 18772014]

21. Miller JS, Shen CJ, Legant WR, Baranski JD, Blakely BL, Chen CS. Bioactive hydrogels made from step-growth derived PEG-peptide macromers. Biomaterials. 2010; 31:3736-3743. [PubMed: 20138664]

22. Okigaki M, Davis C, Falasca M, Harroch S, Felsenfeld DP, Sheetz MP, Schlessinger J. Pyk2 regulates multiple signaling events crucial for macrophage morphology and migration. Proc Natl Acad Sci U S A. 2003; 100:10740-10745. [PubMed: 12960403]

23. Tan JL, Liu W, Nelson CM, Raghavan S, Chen CS. Simple approach to micropattern cells on common culture substrates by tuning substrate wettability. Tissue Eng. 2004; 10:865-872. [PubMed: 15265304]

24. Nelson CM, Pirone DM, Tan JL, Chen CS. Vascular endothelial-cadherin regulates cytoskeletal tension cell spreading, and focal adhesions by stimulating RhoA. Mol Biol Cell. 2004; 15:29432953. [PubMed: 15075376]

25. Duong H, Wu B, Tawil B. Modulation of 3D fibrin matrix stiffness by intrinsic fibrinogenthrombin compositions and by extrinsic cellular activity. Tissue Eng Part A. 2009; 15:1865-1876. [PubMed: 19309239]

26. Ghajar CM, Chen X, Harris JW, Suresh V, Hughes CC, Jeon NL, Putnam AJ, George SC. The effect of matrix density on the regulation of 3-D capillary morphogenesis. Biophys J. 2008; 94:1930-1941. [PubMed: 17993494]

27. Mammoto A, Connor KM, Mammoto T, Yung CW, Huh D, Aderman CM, Mostoslavsky G, Smith LE, Ingber DE. A mechanosensitive transcriptional mechanism that controls angiogenesis. Nature. 2009; 457:1103-1108. [PubMed: 19242469] 
28. Sieminski AL, Hebbel RP, Gooch KJ. The relative magnitudes of endothelial force generation and matrix stiffness modulate capillary morphogenesis in vitro. Exp Cell Res. 2004; 297:574-584. [PubMed: 15212957]

29. Vailhe B, Ronot X, Tracqui P, Usson Y, Tranqui L. In vitro angiogenesis is modulated by the mechanical properties of fibrin gels and is related to alpha(v)beta3 integrin localization. In Vitro Cell Dev Biol Anim. 1997; 33:763-773. [PubMed: 9466681]

30. Beamish JA, Zhu J, Kottke-Marchant K, Marchant RE. The effects of monoacrylated poly(ethylene glycol) on the properties of poly(ethylene glycol) diacrylate hydrogels used for tissue engineering. J Biomed Mater Res A. 2010; 92:441-450. [PubMed: 19191313]

31. Bell SE, Mavila A, Salazar R, Bayless KJ, Kanagala S, Maxwell SA, Davis GE. Differential gene expression during capillary morphogenesis in 3D collagen matrices: regulated expression of genes involved in basement membrane matrix assembly, cell cycle progression, cellular differentiation and G-protein signaling. J Cell Sci. 2001; 114:2755-2773. [PubMed: 11683410]

32. Gerritsen ME, Soriano R, Yang S, Ingle G, Zlot C, Toy K, Winer J, Draksharapu A, Peale F, Wu TD, Williams PM. In silico data filtering to identify new angiogenesis targets from a large in vitro gene profiling data set. Physiol Genomics. 2002; 10:13-20. [PubMed: 12118101]

33. Zhang J, Hughes S. Role of the ephrin and Eph receptor tyrosine kinase families in angiogenesis and development of the cardiovascular system. J Pathol. 2006; 208:453-461. [PubMed: 16470907]

34. Zlot C, Ingle G, Hongo J, Yang S, Sheng Z, Schwall R, Paoni N, Wang F, Peale FV Jr, Gerritsen ME. Stanniocalcin 1 is an autocrine modulator of endothelial angiogenic responses to hepatocyte growth factor. J Biol Chem. 2003; 278:47654-47659. [PubMed: 14500721]

35. Collen A, Hanemaaijer R, Lupu F, Quax PH, van Lent N, Grimbergen J, Peters E, Koolwijk P, van Hinsbergh VW. Membrane-type matrix metalloproteinase-mediated angiogenesis in a fibrincollagen matrix. Blood. 2003; 101:1810-1817. [PubMed: 12393408]

36. Hiraoka N, Allen E, Apel IJ, Gyetko MR, Weiss SJ. Matrix metalloproteinases regulate neovascularization by acting as pericellular fibrinolysins. Cell. 1998; 95:365-377. [PubMed: 9814707]

37. Yasui M, Yamamoto H, Ngan CY, Damdinsuren B, Sugita Y, Fukunaga H, Gu J, Maeda M, Takemasa I, Ikeda M, Fujio Y, Sekimoto M, Matsuura N, Weinstein IB, Monden M. Antisense to cyclin D1 inhibits vascular endothelial growth factor-stimulated growth of vascular endothelial cells: implication of tumor vascularization. Clin Cancer Res. 2006; 12:4720-4729. [PubMed: 16899623]

38. Eliceiri BP, Puente XS, Hood JD, Stupack DG, Schlaepfer DD, Huang XZ, Sheppard D, Cheresh DA. Src-mediated coupling of focal adhesion kinase to integrin alpha(v)beta5 in vascular endothelial growth factor signaling. J Cell Biol. 2002; 157:149-160. [PubMed: 11927607]

39. Braren R, Hu H, Kim YH, Beggs HE, Reichardt LF, Wang R. Endothelial FAK is essential for vascular network stability, cell survival, and lamellipodial formation. J Cell Biol. 2006; 172:151162. [PubMed: 16391003]

40. Shen TL, Park AY, Alcaraz A, Peng X, Jang I, Koni P, Flavell RA, Gu H, Guan JL. Conditional knockout of focal adhesion kinase in endothelial cells reveals its role in angiogenesis and vascular development in late embryogenesis. J Cell Biol. 2005; 169:941-952. [PubMed: 15967814]

41. Avraham HK, Lee TH, Koh Y, Kim TA, Jiang S, Sussman M, Samarel AM, Avraham S. Vascular endothelial growth factor regulates focal adhesion assembly in human brain microvascular endothelial cells through activation of the focal adhesion kinase and related adhesion focal tyrosine kinase. J Biol Chem. 2003; 278:36661-36668. [PubMed: 12844492]

42. Weis SM, Lim ST, Lutu-Fuga KM, Barnes LA, Chen XL, Gothert JR, Shen TL, Guan JL, Schlaepfer DD, Cheresh DA. Compensatory role for Pyk2 during angiogenesis in adult mice lacking endothelial cell FAK. J Cell Biol. 2008; 181:43-50. [PubMed: 18391070]

43. Lev S, Moreno H, Martinez R, Canoll P, Peles E, Musacchio JM, Plowman GD, Rudy B, Schlessinger J. Protein tyrosine kinase PYK2 involved in $\mathrm{Ca}(2+)$-induced regulation of ion channel and MAP kinase functions. Nature. 1995; 376:737-745. [PubMed: 7544443]

44. Zheng C, Xing Z, Bian ZC, Guo C, Akbay A, Warner L, Guan JL. Differential regulation of Pyk2 and focal adhesion kinase (FAK). The C-terminal domain of FAK confers response to cell adhesion. J Biol Chem. 1998; 273:2384-2389. [PubMed: 9442086] 
45. Avraham S, London R, Fu Y, Ota S, Hiregowdara D, Li J, Jiang S, Pasztor LM, White RA, Groopman JE, Avraham H. Identification and characterization of a novel related adhesion focal tyrosine kinase (RAFTK) from megakaryocytes and brain. J Biol Chem. 1995; 270:27742-27751. [PubMed: 7499242]

46. Sasaki H, Nagura K, Ishino M, Tobioka H, Kotani K, Sasaki T. Cloning and characterization of cell adhesion kinase beta, a novel protein-tyrosine kinase of the focal adhesion kinase subfamily. $\mathrm{J}$ Biol Chem. 1995; 270:21206-21219. [PubMed: 7673154]

47. van Buul JD, Anthony EC, Fernandez-Borja M, Burridge K, Hordijk PL. Proline-rich tyrosine kinase 2 (Pyk2) mediates vascular endothelial-cadherin-based cell-cell adhesion by regulating beta-catenin tyrosine phosphorylation. J Biol Chem. 2005; 280:21129-21136. [PubMed: 15778498]

48. Matsui A, Okigaki M, Amano K, Adachi Y, Jin D, Takai S, Yamashita T, Kawashima S, Kurihara T, Miyazaki M, Tateishi K, Matsunaga S, Katsume A, Honshou S, Takahashi T, Matoba S, Kusaba T, Tatsumi T, Matsubara H. Central role of calcium-dependent tyrosine kinase PYK2 in endothelial nitric oxide synthase-mediated angiogenic response and vascular function. Circulation. 2007; 116:1041-1051. [PubMed: 17698736]

49. Tang H, Hao Q, Fitzgerald T, Sasaki T, Landon EJ, Inagami T. Pyk2/CAKbeta tyrosine kinase activity-mediated angiogenesis of pulmonary vascular endothelial cells. J Biol Chem. 2002; 277:5441-5447. [PubMed: 11739395]

50. Bonnette PC, Robinson BS, Silva JC, Stokes MP, Brosius AD, Baumann A, Buckbinder L. Phosphoproteomic characterization of PYK2 signaling pathways involved in osteogenesis. J Proteomics. 2010; 73:1306-1320. [PubMed: 20116462]

51. Slack-Davis JK, Martin KH, Tilghman RW, Iwanicki M, Ung EJ, Autry C, Luzzio MJ, Cooper B, Kath JC, Roberts WG, Parsons JT. Cellular characterization of a novel focal adhesion kinase inhibitor. J Biol Chem. 2007; 282:14845-14852. [PubMed: 17395594]

52. Ferrara N, Kerbel RS. Angiogenesis as a therapeutic target. Nature. 2005; 438:967-974. [PubMed: 16355214]

53. Paszek MJ, Zahir N, Johnson KR, Lakins JN, Rozenberg GI, Gefen A, Reinhart-King CA, Margulies SS, Dembo M, Boettiger D, Hammer DA, Weaver VM. Tensional homeostasis and the malignant phenotype. Cancer Cell. 2005; 8:241-254. [PubMed: 16169468]

54. Reynolds AR, Hart IR, Watson AR, Welti JC, Silva RG, Robinson SD, Da Violante G, Gourlaouen M, Salih M, Jones MC, Jones DT, Saunders G, Kostourou V, Perron-Sierra F, Norman JC, Tucker GC, Hodivala-Dilke KM. Stimulation of tumor growth and angiogenesis by low concentrations of RGD-mimetic integrin inhibitors. Nat Med. 2009; 15:392-400. [PubMed: 19305413]

55. Yana I, Sagara H, Takaki S, Takatsu K, Nakamura K, Nakao K, Katsuki M, Taniguchi S, Aoki T, Sato H, Weiss SJ, Seiki M. Crosstalk between neovessels and mural cells directs the site-specific expression of MT1-MMP to endothelial tip cells. J Cell Sci. 2007; 120:1607-1614. [PubMed: 17405818]

56. Gerhardt H, Golding M, Fruttiger M, Ruhrberg C, Lundkvist A, Abramsson A, Jeltsch M, Mitchell C, Alitalo K, Shima D, Betsholtz C. VEGF guides angiogenic sprouting utilizing endothelial tip cell filopodia. J Cell Biol. 2003; 161:1163-1177. [PubMed: 12810700]

57. Carmeliet P. VEGF as a key mediator of angiogenesis in cancer. Oncology. 2005; 69 Suppl 3:410. [PubMed: 16301830]

58. Guan JL, Trevithick JE, Hynes RO. Fibronectin/integrin interaction induces tyrosine phosphorylation of a 120-kDa protein. Cell Regul. 1991; 2:951-964. [PubMed: 1725602]

59. Gilmore AP, Romer LH. Inhibition of focal adhesion kinase (FAK) signaling in focal adhesions decreases cell motility and proliferation. Mol Biol Cell. 1996; 7:1209-1224. [PubMed: 8856665]

60. Parsons JT. Focal adhesion kinase: the first ten years. J Cell Sci. 2003; 116:1409-1416. [PubMed: 12640026]

61. Holmes DI, Zachary IC. Vascular endothelial growth factor regulates stanniocalcin-1 expression via neuropilin-1-dependent regulation of KDR and synergism with fibroblast growth factor-2. Cell Signal. 2008; 20:569-579. [PubMed: 18164591]

62. Avraham H, Park SY, Schinkmann K, Avraham S. RAFTK/Pyk2-mediated cellular signalling. Cell Signal. 2000; 12:123-133. [PubMed: 10704819] 
63. Brizzi MF, Defilippi P, Rosso A, Venturino M, Garbarino G, Miyajima A, Silengo L, Tarone G, Pegoraro L. Integrin-mediated adhesion of endothelial cells induces JAK2 and STAT5A activation: role in the control of c-fos gene expression. Mol Biol Cell. 1999; 10:3463-3471. [PubMed: 10512880]

64. Dudley AC, Thomas D, Best J, Jenkins A. A VEGF/JAK2/STAT5 axis may partially mediate endothelial cell tolerance to hypoxia. Biochem J. 2005; 390:427-436. [PubMed: 15918795]

65. Shaut CA, Saneyoshi C, Morgan EA, Knosp WM, Sexton DR, Stadler HS. HOXA13 directly regulates EphA6 and EphA7 expression in the genital tubercle vascular endothelia. Dev Dyn. 2007; 236:951-960. [PubMed: 17304517] 


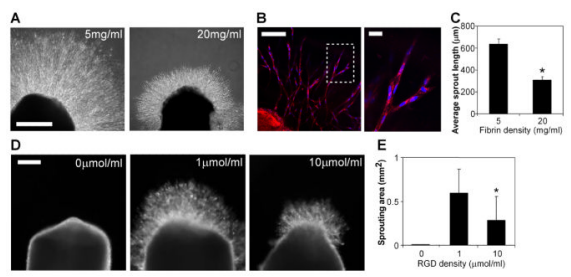

Figure 1. Decreased adhesive ligand density enhances angiogenic sprouting (A) Sprouting of chick aortic rings embedded in $5 \mathrm{mg} / \mathrm{ml}$ (left) versus $20 \mathrm{mg} / \mathrm{ml}$ (right) fibrin in EGM-2 medium at 48 hours, bar=500 $\mu \mathrm{m}$. (B) Endothelial cells in sprouts labeled with lectin (red) and Hoechst 33342 (blue), with region outlined by dotted line magnified on the right. Bar (left image), $100 \mu \mathrm{m}$; bar (right image), $20 \mu \mathrm{m}$. (C) Quantification of average sprout length for chick aortic rings in $5 \mathrm{mg} / \mathrm{ml}$ versus $20 \mathrm{mg} / \mathrm{ml}$ fibrin. Graph represents means $\pm \operatorname{SEM}(\mathrm{n}=4)$, with each experiment averaged over at least 3 aortic rings. (D) Sprouting of chick aortic rings embedded in PEGDAAm gels with $0 \mu \mathrm{mol} / \mathrm{ml}$ adhesive RGDS + $10 \mu \mathrm{mol} / \mathrm{ml}$ non-adhesive RGES (left), 1 umol/ml RGDS + 9 umol $/ \mathrm{ml}$ RGES (middle), and $10 \mathrm{umol} / \mathrm{ml} \mathrm{RGDS}+0 \mathrm{umol} / \mathrm{ml}$ RGES (right) in EGM-2 medium at 48 hours, bar $=200 \mu \mathrm{m}$. (E) Quantification of sprouting area for chick aortic rings in PEGDAAm gels of varying RGDS density. Graph represents means $\pm \mathrm{SD}(\mathrm{n}=8)$. *, $\mathrm{p}<0.05$, compared to 1 umol/ml RGDS, as calculated by one-way ANOVA and post-hoc Tukey's HSD test. 


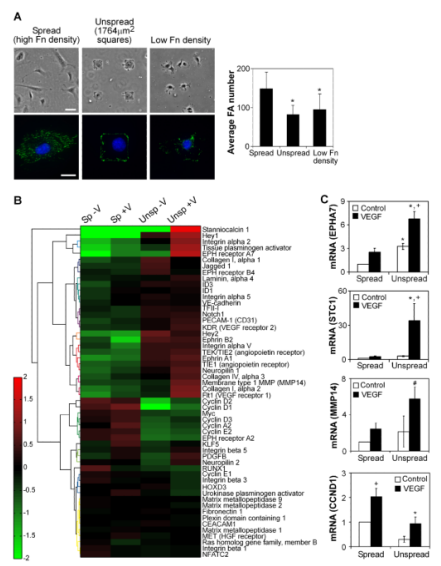

Figure 2. Cell adhesion and spreading regulate the expression of genes associated with angiogenesis

(A) Cell adhesion is controlled by constraining cells to micropatterned islands of fibronectin ("unspread," $1764 \mu \mathrm{m}^{2}$ area, high density $20 \mu \mathrm{g} / \mathrm{ml}$ fibronectin) or reducing fibronectin density $(5 \mu \mathrm{g} / \mathrm{ml})$, as compared to fully spread cells on high density fibronectin ("spread"). Phase images in top row, bar=50 $\mu \mathrm{m}$. Immunofluorescent images in bottom row with vinculin (green) and Hoechst 33342 (blue), bar $=20 \mu \mathrm{m}$. The average focal adhesion number per cell is quantified for each condition (means $\pm \mathrm{SD}, \mathrm{n}=15$ cells per condition). ${ }^{*}, \mathrm{p}<0.05$ versus high fibronectin density, as calculated by one-way ANOVA and post-hoc Tukey's HSD test. (B) Heatmap of expression of genes associated with angiogenesis in four conditions (spread no VEGF, spread with VEGF, unspread no VEGF, unspread with VEGF) after 18 hours of culture. Heatmap values represent log-transformed ratios of expression in one condition to the average expression value over all conditions for a given gene, averaged over three replicates. Genes are clustered based on similarities in expression patterns using Ward's hierarchical clustering method. (C) HUVECs were cultured as spread or unspread, in starvation medium with or without $25 \mathrm{ng} / \mathrm{ml}$ VEGF for 16-18 hours and analyzed for expression of select genes by quantitative real-time PCR analysis (EPHA7=Eph Receptor A7, MMP14=Membrane type 1 MMP, STC1=Stanniocalcin 1, CCND1=Cyclin D1). Data represent means \pm SEM $(n \geq 3)$. ${ }^{*}, p<0.05$ compared to the spread condition, and,$+ \mathrm{p}<0.05$ compared to no VEGF control, as calculated by two-way ANOVA and post-hoc Tukey's HSD test. \#, p<0.05 compared to the spread condition, as calculated by Student's t-test (not significant by ANOVA). 

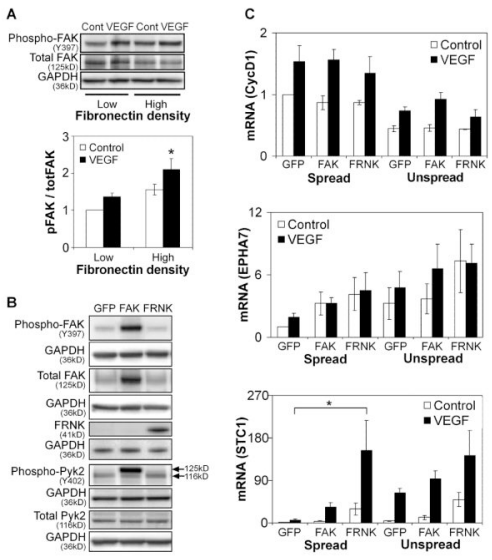

Figure 3. FAK is not a major regulator of limited adhesion-induced angiogenic gene expression (A) Western blot of FAK phosphorylation in HUVECs cultured on high $(20 \mu \mathrm{g} / \mathrm{ml})$ and low $(5 \mu \mathrm{g} / \mathrm{ml})$ density fibronectin-coated surfaces with or without VEGF stimulation for 30 minutes. Data represent means \pm SEM $(n=3)$. *,$p<0.05$ compared to low density fibronectin, as calculated by two-way ANOVA and post-hoc Tukey's HSD test. (B) Western blot of FAK and Pyk2 phosphorylation in GFP-, FAK-, and FRNK-overexpressing HUVECs cultured on high density fibronectin without VEGF stimulation. Note that for phospho-Pyk2, the antibody interacts non-specifically with FAK and thus results in a higher molecular weight band $(125 \mathrm{kD})$ when FAK is overexpressed; the Pyk2 Y402 band is the lower molecular weight band at $116 \mathrm{kD}$. (C) Gene expression of GFP-, FRNK-, and FAKoverexpressing HUVECs after 16-18 hours of culture in spread or unspread conditions with or without VEGF stimulation. Data represent means \pm SEM $(n=3)$. *, $p<0.05$ compared to GFP, as calculated by three-way ANOVA and post-hoc Tukey's HSD test. 
A

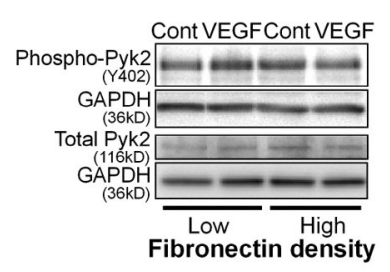

B

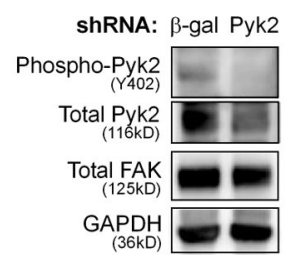

C

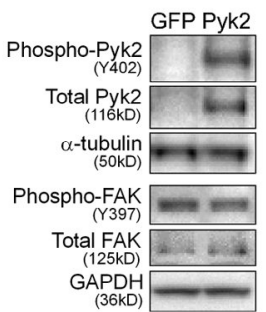

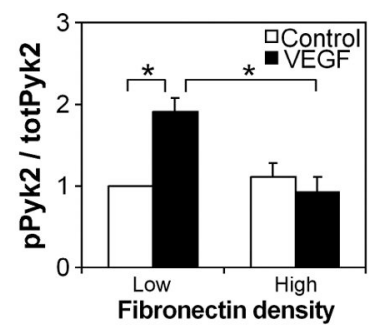
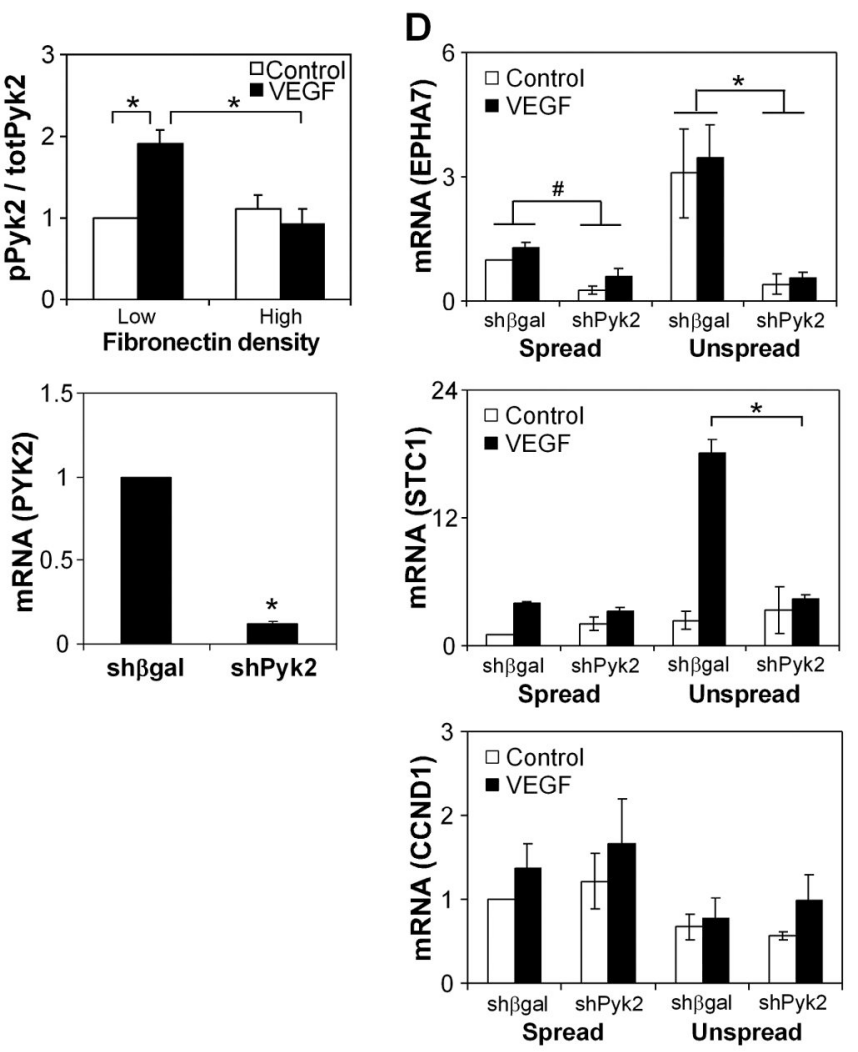

E
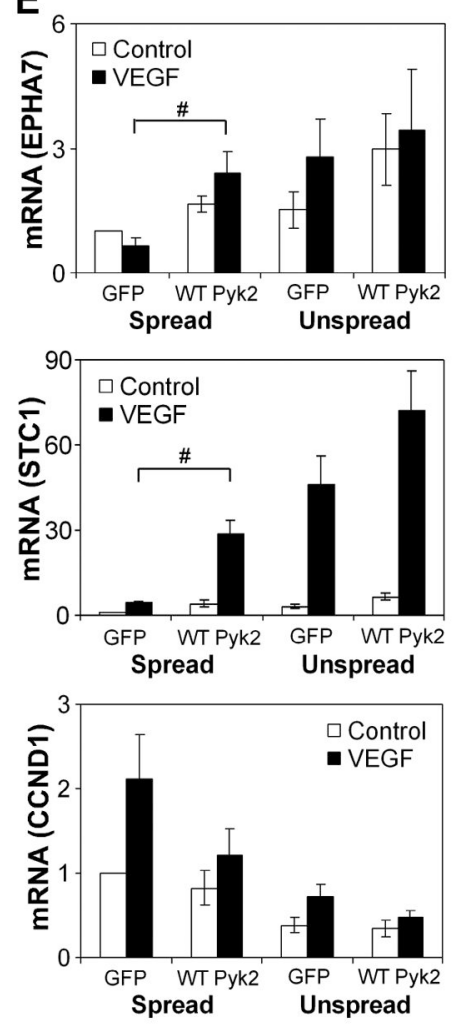

Figure 4. Pyk2 regulates the expression of genes associated with angiogenesis

(A) Western blot of Pyk2 phosphorylation in HUVECs cultured on high $(20 \mu \mathrm{g} / \mathrm{ml})$ and low $(5 \mu \mathrm{g} / \mathrm{ml})$ density fibronectin-coated surfaces with or without VEGF stimulation for 30 minutes. Data represent means \pm SEM $(n=4)$ and $*, p<0.05$, as calculated by two-way ANOVA and post-hoc Tukey's HSD test. (B) Pyk2 and FAK protein expression by Western blot (left) and Pyk2 mRNA (right) in HUVECs transfected with control ( $\beta$-gal) versus Pyk2 shRNA cultured on high density fibronectin without VEGF stimulation. mRNA graph data represent means \pm SEM $(\mathrm{n}=4)$. *, $\mathrm{p}<0.05$, as calculated by Student's t-test. (C) Western blot of Pyk2 and FAK phosphorylation in GFP- and Pyk2-overexpressing HUVECs cultured on high density fibronectin without VEGF stimulation. (D) Gene expression of HUVECs transfected with control versus Pyk2 shRNA after 16-18 hours of culture in spread or unspread conditions with or without VEGF stimulation. Data represent means $\pm \operatorname{SEM}(n=3)$. *, p $<0.05$, as calculated by three-way ANOVA and post-hoc Tukey's HSD test. (E) Gene expression of GFP- and Pyk2-overexpressing HUVECs after 16-18 hours of culture in spread or unspread conditions with or without VEGF stimulation. Data represent means \pm SEM ( $\mathrm{n}=3)$. \#, $\mathrm{p}<0.05$, as calculated by Student's t-test (not significant by ANOVA). 


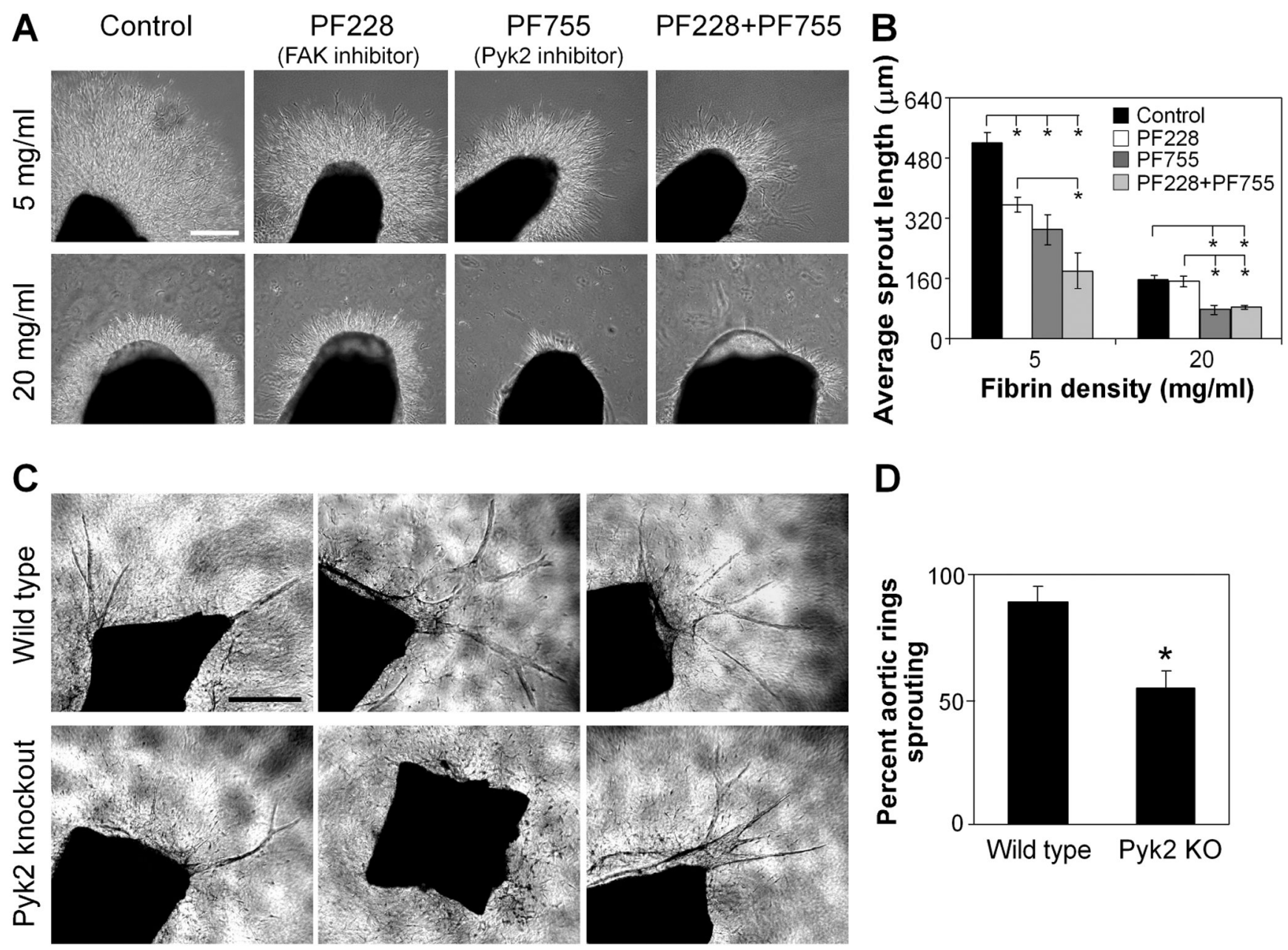

Figure 5. Pyk2 regulates angiogenic sprouting

(A) Sprouting of chick aortic rings in the presence of DMSO control, $500 \mathrm{nM}$ PF228, 500 nM PF755, or both $500 \mathrm{nM}$ PF228 and $500 \mathrm{nM}$ PF755 in low $(5 \mathrm{mg} / \mathrm{ml})$ versus high $(20 \mathrm{mg} /$ $\mathrm{ml}$ ) density fibrin in EGM-2 medium at 48 hours, bar=300 $\mu \mathrm{m}$. (B) Quantification of average sprout length for aortic rings in (A). Data represent means \pm SEM $(n=3)$, with each experiment averaged over at least 2 aortic rings. *, $\mathrm{p}<0.05$, as calculated by one-way ANOVA and post-hoc Tukey's HSD test. (C) Sprouting of aortic rings isolated from Pyk2 knockout versus wild type mice in $2.5 \mathrm{mg} / \mathrm{ml}$ collagen I gels in VEGF-containing medium at 8 days, bar $=500 \mu \mathrm{m}$. (D) Quantification of percent of aortic rings with sprouting in the conditions in (C). Data represent means \pm SEM $(n=4)$, with each experiment averaged over at least 8 aortic rings. *, $\mathrm{p}<0.05$, as calculated by Student's t-test. 